\title{
Comparative analysis of gene expression profiles in children with type 1 diabetes mellitus
}

\author{
LIWEI QIAN $^{1 *}$, HONGLEI SHI ${ }^{1 *}$ and MEILI DING ${ }^{2}$ \\ ${ }^{1}$ Department of Pediatrics, The Second People's Hospital of Liaocheng, Liaocheng, Shandong 252000; \\ ${ }^{2}$ Department of Pediatrics, Shandong Jining No. 1 People's Hospital, Jining, Shandong 272011, P.R. China
}

Received December 20, 2017; Accepted June 22, 2018

DOI: $10.3892 / \mathrm{mmr} .2019 .10099$

\begin{abstract}
Type 1 diabetes (T1D) is an autoimmune disease that is typically diagnosed in children. The aim of the present study was to identify potential genes involved in the pathogenesis of childhood T1D. Two datasets of mRNA expression in children with T1D were obtained from the Gene Expression Omnibus (GEO). Differentially expressed genes (DEGs) in children with T1D were identified. Functional analysis was performed and a protein-protein interaction (PPI) network was constructed, as was a transcription factor (TF)-target network. The expression of selected DEGs was further assessed using reverse transcription-quantitative polymerase chain reaction (RT-qPCR) analysis. Electronic validation and diagnostic value analysis of the identified DEGs [cytokine inducible $\mathrm{SH} 2$ containing protein (CISH), SR-related CTD associated factor 11 (SCAF11), estrogen receptor 1 (ESR1), Rho GTPase activating protein 25 (ARHGAP25), major histocompatibility complex, class II, DR $\beta 4$ (HLA-DRB4) and interleukin 23 subunit $\alpha$
\end{abstract}

Correspondence to: Dr Meili Ding, Department of Pediatrics, Shandong Jining No. 1 People's Hospital, 6 Jiankang Road, Jining, Shandong 272011, P.R. China

E-mail: meilidingjn@163.com

\section{*Contributed equally}

Abbreviations: SOCS, CIS/suppressors of cytokine signaling; $\mathrm{CISH}$, cytokine inducible $\mathrm{SH} 2$ containing protein; DEGs, differentially expressed genes; ESR1, estrogen receptor 1; GEO, gene expression omnibus; HNRNPD, heterogeneous nuclear ribonucleoprotein D; ITGA4, integrin subunit $\alpha 4$; IL23A, interleukin 23 subunit $\alpha$; HLA, major histocompatibility complex; HLA-DRB4, major histocompatibility complex, class II, DR $\beta 4$; PRKAA1, protein kinase AMP-activated catalytic subunit $\alpha 1$; PPI, protein-protein interaction; RT-qPCR, quantitative reverse transcription-polymerase chain reaction; ARHGAP25, Rho GTPase activating protein 25; SCAF11, SR-related CTD associated factor 11; TFs, transcription factors; TAP2, transporter 2, ATP binding cassette subfamily B member; T1D, type 1 diabetes

Keywords: mRNA expression profiles, children with type 1 diabetes, protein-protein interaction, transcription factor-targets
(IL23A)] was performed in the GEO dataset. Compared with the normal control group, a total of 1,467 DEGs with $\mathrm{P}<0.05$ were identified in children with T1D. CISH and SCAF11 were determined to be the most up- and downregulated genes, respectively. Heterogeneous nuclear ribonucleoprotein D (HNRNPD; degree=33), protein kinase AMP-activated catalytic subunit $\alpha 1$ (PRKAA1; degree=11), integrin subunit $\alpha 4$ (ITGA4; degree=8) and ESR1 (degree=8) were identified in the PPI network as high-degree genes. ARHGAP25 (degree=12), HNRNPD (degree=10), HLA-DRB4 (degree=10) and IL23A (degree=9) were high-degree genes identified in the TF-target network. RT-qPCR revealed that the expression of HNRNPD, PRKAA1, ITGA4 and transporter 2, ATP binding cassette subfamily $\mathrm{B}$ member was consistent with the results of the integrated analysis. Furthermore, the results of the electronic validation were consistent with the bioinformatics analysis. SCAF11, CISH and ARHGAP25 were identified to possess value as potential diagnostic markers for children with T1D. In conclusion, identifying DEGs in children with T1D may contribute to our understanding of its pathogenesis, and such DEGs may be used as diagnostic biomarkers for children with T1D.

\section{Introduction}

Diabetes mellitus is defined as hyperglycemia resulting from impaired insulin secretion and peripheral insulin resistance (1). Numerous types of diabetes mellitus exist, including type 1 diabetes (T1D), type 2 diabetes (T2D) and gestational diabetes mellitus (1). T1D is an organ-specific disease that is characterized by the autoimmune destruction of pancreatic $\beta$ cells leading to insulin deficiency (2). In addition, islet infiltration by macrophages, lymphocytes, dendritic cells and natural killer (NK) cells is commonly observed in T1D, as is the overexpression of a number of immune system genes $(3,4)$.

T1D primarily affects children and young adults, and symptoms are typically more severe in children compared with adults. It has been reported that T1D accounts for $80-90 \%$ of diabetes in children and adolescents $(5,6)$. The onset of T1D is frequently sudden in children and adolescents, and a number of symptoms are exhibited, including enuresis, polyuria, polydipsia, polyphagia, extreme tiredness, blurred vision, sudden weight loss, lack of energy, slow-healing wounds and recurrent infections (7), with severe dehydration and diabetic ketoacidosis. Patients with T1D are additionally at a higher risk 
of developing other autoimmune disorders, including vitiligo, Addison's disease, Graves' disease, celiac sprue, Hashimoto's thyroiditis, myasthenia gravis, autoimmune hepatitis and pernicious anemia (8). Furthermore, patients with T1D require long-term insulin treatment and have an increased risk of stroke, blindness, kidney failure and heart disease, all of which contribute to early patient mortality.

In order to reduce patient mortality, it is important to identify potential pathological genes that serve a role in the pathogenesis of T1D in children. The present study identified T1D-associated alterations in gene expression by integrating mRNA expression datasets from children with T1D from the Gene Expression Omnibus (GEO) database. Differentially expressed genes (DEGs) in children with T1D were identified. Functional analysis was performed and a protein-protein interaction (PPI) network was constructed, followed by the transcription factor (TF)-target network construction. The expression of selected DEGs was further assessed using reverse transcription-quantitative polymerase chain reaction (RT-qPCR) analysis. Electronic validation and diagnostic value analysis of the identified DEGs [cytokine inducible SH2 containing protein (CISH), SR-related CTD associated factor 11 (SCAF11), estrogen receptor 1 (ESR1), Rho GTPase activating protein 25 (ARHGAP25), major histocompatibility complex, class II, DR $\beta 4$ (HLA-DRB4) and interleukin 23 subunit $\alpha$ (IL23A)] was performed in the GEO dataset. The results of the present study may improve diagnostic and treatment methods for children with T1D.

\section{Materials and methods}

Datasets. In the present study, datasets from the GEO database (http://www.ncbi.nlm.nih.gov/geo) were searched using the key words 'diabetes mellitus, type 1' [MeSH Terms] OR 'type 1 diabetes' [All Fields] AND 'Homo sapiens' [porgn] AND 'gse' [Filter]. The study type may be described as 'expression profiling by array'. All selected datasets contained genome-wide expression data of the case group and/or normal group blood samples. In blood samples, monocytes were used for RNA sequencing analysis. A total of two datasets, GSE9006 and GSE33440, were included in the final analysis (Table I).

Analysis of DEGs. Raw expression data were downloaded and the limma (3.3.3) (9) and metaMA packages (3.3.0) (10) were used to identify the DEGs. The inverse normal method was used to combine P-values in metaMA. The threshold for DEGs was set at $\mathrm{P}<0.05$.

Functional annotation analysis of DEGs. To elucidate the biological function and signaling pathways of DEGs, GeneCoDis3 (3.3.0) (http://genecodis.cnb.csic.es/analysis) software was used for Gene Ontology (GO; http://www.geneontology.org/) annotation and Kyoto Encyclopedia of Genes Genomes (KEGG; http://www.genome.jp/kegg/pathway.html) pathway enrichment. The thresholds of the GO function and KEGG pathways were $\mathrm{P}<0.05$.

PPI network construction. Studying the interactions between proteins may aid elucidation of the underlying molecular mechanisms responsible for the pathogenesis of T1D in children. In order to gain insights into the interaction between proteins encoded by DEGs and other proteins, the predicted interactions between the top 100 proteins encoded by DEGs (50 upregulated and 50 downregulated) were retrieved from the BioGRID database (http://thebiogrid.org). The PPI network was subsequently visualized using Cytoscape Software (3.3.0) (http://cytoscape.org). Nodes in the PPI network denote proteins and edges denote interactions.

Analysis of potential TFs that target DEGs. TFs serve a crucial role in the regulation of gene expression. The human genome TFs and motifs of genomic binding sites were downloaded from TRANSFAC (http://genexplain.com/transfac). The $2 \mathrm{~kb}$ sequences in the upstream promoter regions of the DEGs were downloaded from the University of California, Santa Cruz (Santa Cruz, CA, USA; http://www.genome.ucsc. edu/cgi-bin/hgTables) to determine potential TF target sites. Finally, the transcriptional regulatory network was visualized using Cytoscape software.

$R T-q P C R$ in vitro. A total of five children with T1D and five control individuals were recruited for the present study. All children were Han and the sex ratio was 6:4 (male:female). No additional auto-immune diseases were diagnosed in any subjects. Clinical data for T1D patients is presented in Table II. Ethical approval was obtained from the Ethics Committee of Shandong Jining No. 1 People's Hospital (Jining, China) and informed written consent was obtained from all subjects.

Total RNA was extracted from $0.25 \mathrm{ml}$ blood samples using the RNAliquid Reagent (Tiangen Biotech Co., Ltd., Beijing, China ), according to the manufacturer's protocols. A total of $1 \mu \mathrm{g}$ RNA was used with FastQuant Reverse Transcriptase (Tiangen Biotech Co., Ltd.) to synthesize cDNA for $5 \mathrm{~min}$ at $65^{\circ} \mathrm{C}$ followed by $60 \mathrm{~min}$ at $42^{\circ} \mathrm{C}$ and $5 \mathrm{~min}$ at $72^{\circ} \mathrm{C}$. qPCR was performed in an ABI 7300 Real-time PCR system with SYBR ${ }^{\circledR}$ Green PCR Master Mix (Tiangen Biotech Co., Ltd.). The thermocycling conditions were as follows: $15 \mathrm{~min}$ at $95^{\circ} \mathrm{C}$ followed by 40 cycles of $10 \mathrm{sec}$ at $95^{\circ} \mathrm{C}, 30 \mathrm{sec}$ at $55^{\circ} \mathrm{C}, 32 \mathrm{sec}$ at $72^{\circ} \mathrm{C}$, and $15 \mathrm{sec}$ at $95^{\circ} \mathrm{C}, 60 \mathrm{sec}$ at $60^{\circ} \mathrm{C}, 15 \mathrm{sec}$ extension at $95^{\circ} \mathrm{C}$. All reactions were performed in triplicate. GAPDH was used as the internal reference and relative gene expression was calculated as a fold-change. The sequences of reverse and forward primers for all of the genes analyzed were as follows: HNRNPD (forward: GAGGCGTGGGTTCTGCTTTAT, reverse: AGATCCCCA CTGTTGCTGTTG); PRKAA1 (forward: TTGAAACCTGAA AATGTCCTGCT, reverse: GGTGAGCCACAACTTGTT CTT); ITGA4 (forward: AGCCCTAATGGAGAACCTTGT, reverse: CCAGTGGGGAGCTTATTTTCAT); TAP2 (forward: CACCTACACCATGTCTCGAATC, reverse: AGTTACTCA TCAGGGTGGTATCC); GAPDH (forward: GGAGCGAGA TCCCTCCAAAAT, reverse: GGCTGTTGTCATACTTCT CATGG). The experiment was repeated three times. The relative expression of genes was calculated using the $2^{-\Delta \Delta C q}$ method (11). The statistical analyses were performed using GraphPad Prism 2.0 (GraphPad Software, Inc., La Jolla, CA, USA).

Electronic validation of DEGs and receiver operating characteristic $(R O C)$ analysis. In order to determine the expression of DEGs, including CISH, SCAF11, ESR1, ARHGAP25, 
Table I. GEO datasets.

\begin{tabular}{|c|c|c|c|c|}
\hline Author, year & GEO accession no. & Platform & Samples (N:P) & (Refs.) \\
\hline Kaizer et al, 2007 & GSE9006 & $\begin{array}{l}\text { GPL96 [HG-U133A] Affymetrix } \\
\text { Human Genome U133A Array }\end{array}$ & $24: 81$ & $(62)$ \\
\hline Irvine et al, 2012 & GSE33440 & $\begin{array}{l}\text { GPL6947 Illumina HumanHT-12 } \\
\text { V3.0 expression beadchip }\end{array}$ & $6: 16$ & (63) \\
\hline
\end{tabular}

GEO, gene expression omnibus; $\mathrm{N}$, normal controls; $\mathrm{P}$, patients with type 1 diabetes mellitus.

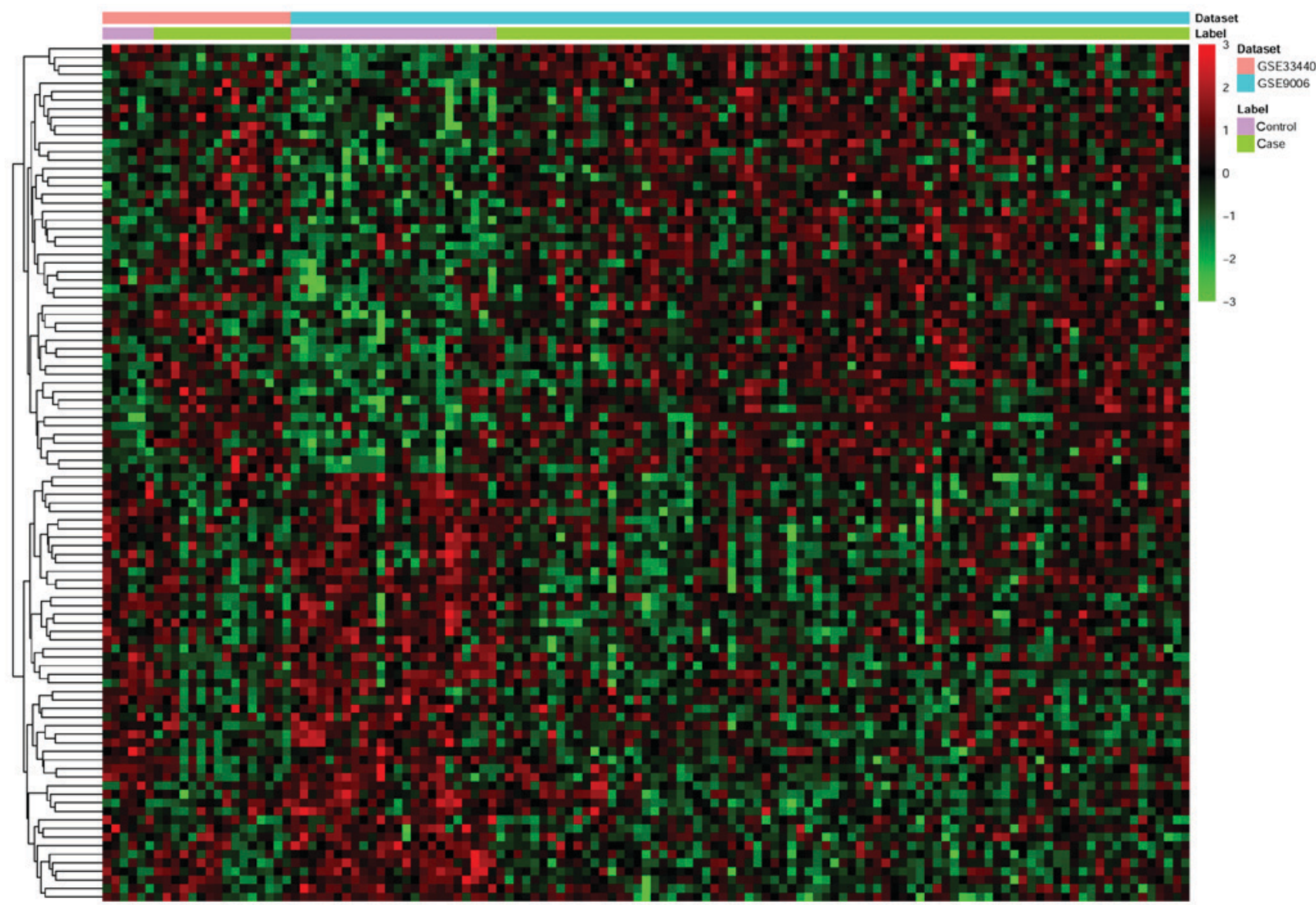

Figure 1. Heat map of the top 100 DEGs. Hierarchal clustering was performed using the complete linkage method together with the Euclidean distance. Each row represents a DEG and each column represents a sample. The DEG clustering tree is presented on the right and the color scale illustrates the relative level of DEG expression: Red, below the reference channel; green, above the reference channel. DEGs, differentially expressed genes.

HLA-DRB4 and IL23A, the GEO dataset was subjected to electronic validation. The results are presented as box plots. The pROC package in R 2.0 (http://web.expasy.org/pROC/) (12) was used for ROC analysis to assess the diagnostic value of these genes. The area under the curve (AUC) was calculated and the ROC curve was constructed.

\section{Results}

$D E G$ analysis. Raw expression profiles were downloaded from the data portal of the GEO database. A total of 1,467 DEGs were identified, comprising 804 upregulated genes and 663 downregulated genes. The top 10 up- and downregulated
DEGs are listed in Table III and a heat map of the top 100 DEGs is presented in Fig. 1.

Functional and pathway enrichment analyses of DEGs. To investigate the biological functions of the identified DEGs in children with T1D, GO term and KEGG pathway enrichment analyses were performed. 'Signal transduction', 'regulation of transcription, DNA-dependent', 'positive regulation of transcription from RNA polymerase II promoter', 'blood coagulation' and 'apoptotic process' were the most significantly enriched biological processes. 'Protein binding', 'nucleotide binding' and 'metal ion binding' were the most markedly enriched molecular functions, and 'cytoplasm', 'nucleus' and 


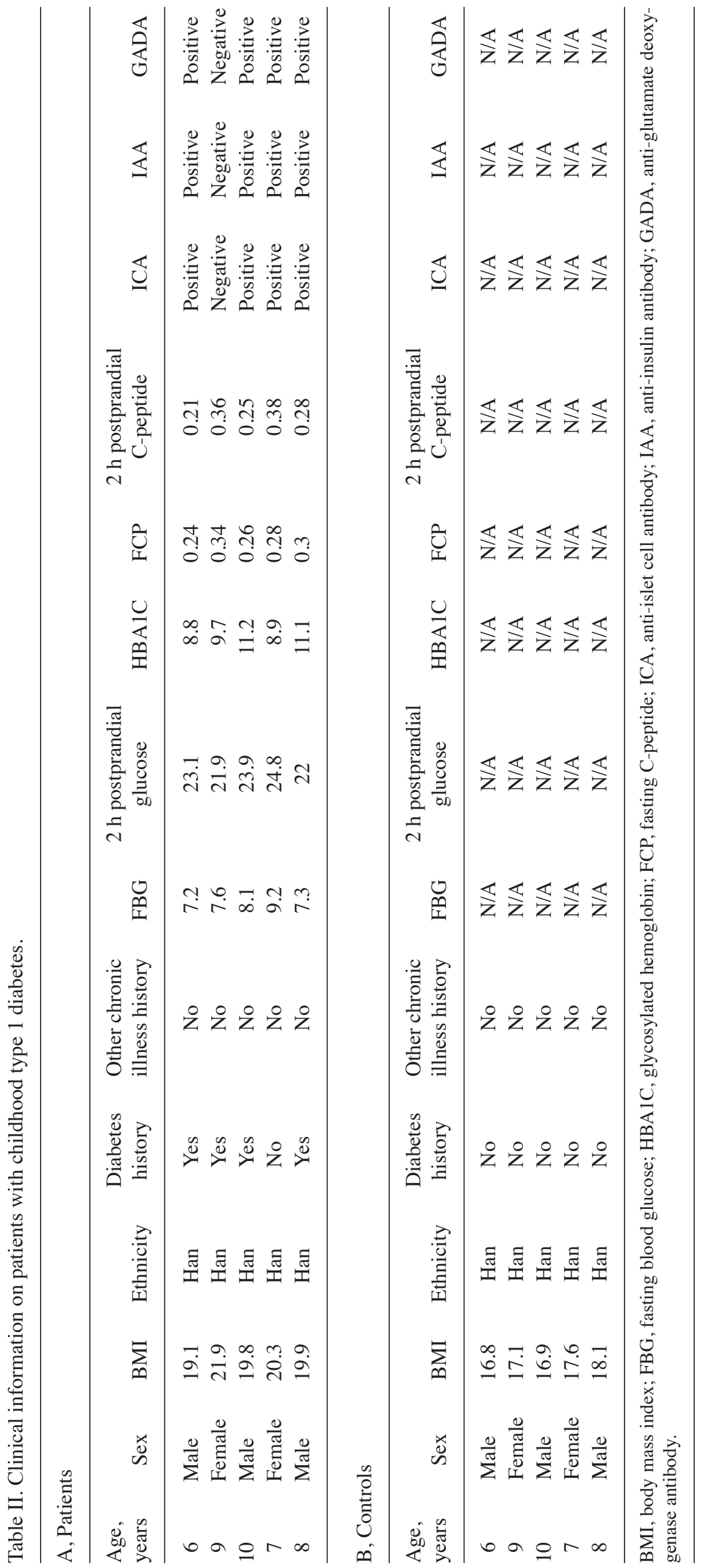




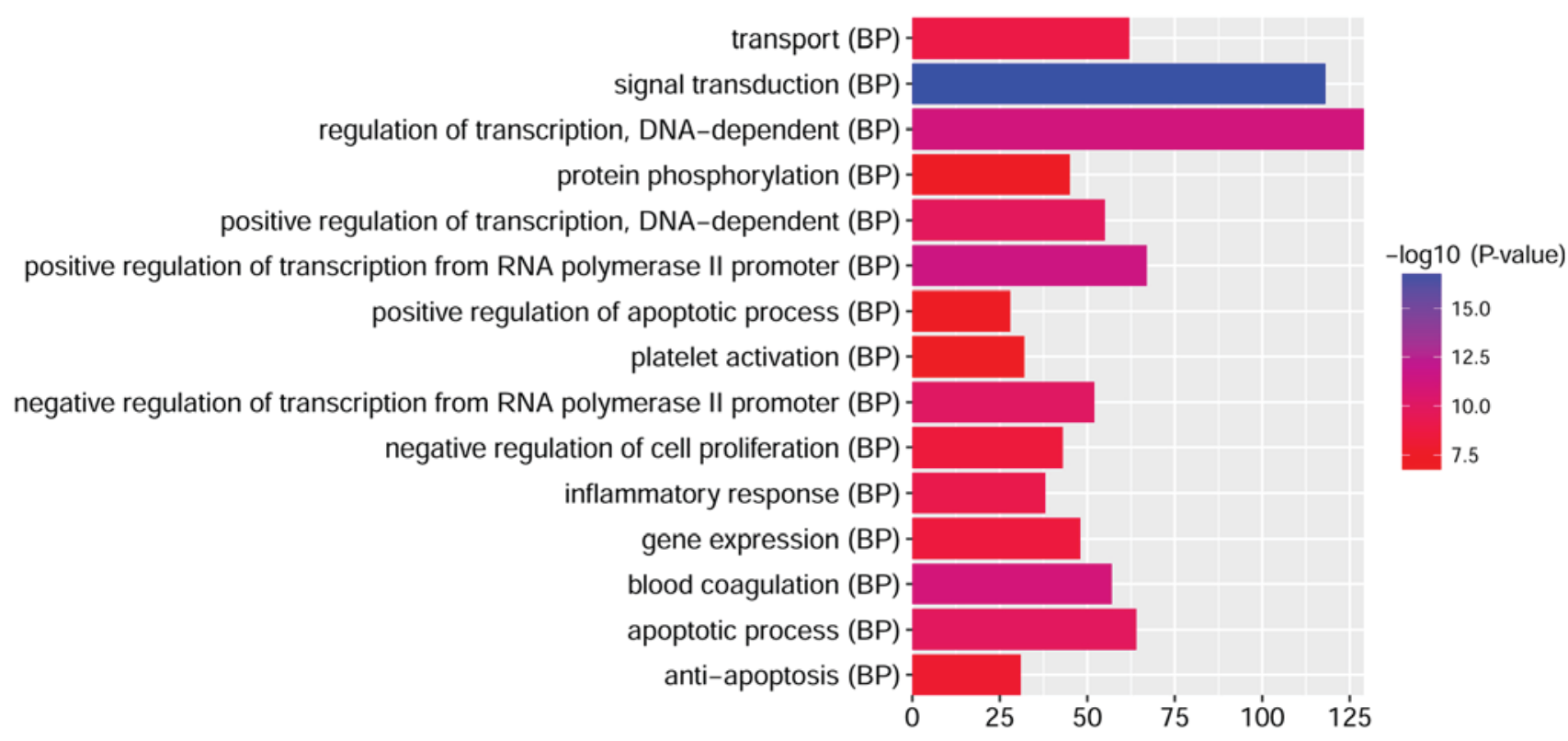

Figure 2. Top 15 significantly enriched BPs of differentially expressed genes. The x-axis represents the number of differentially expressed genes. BP, biological process.

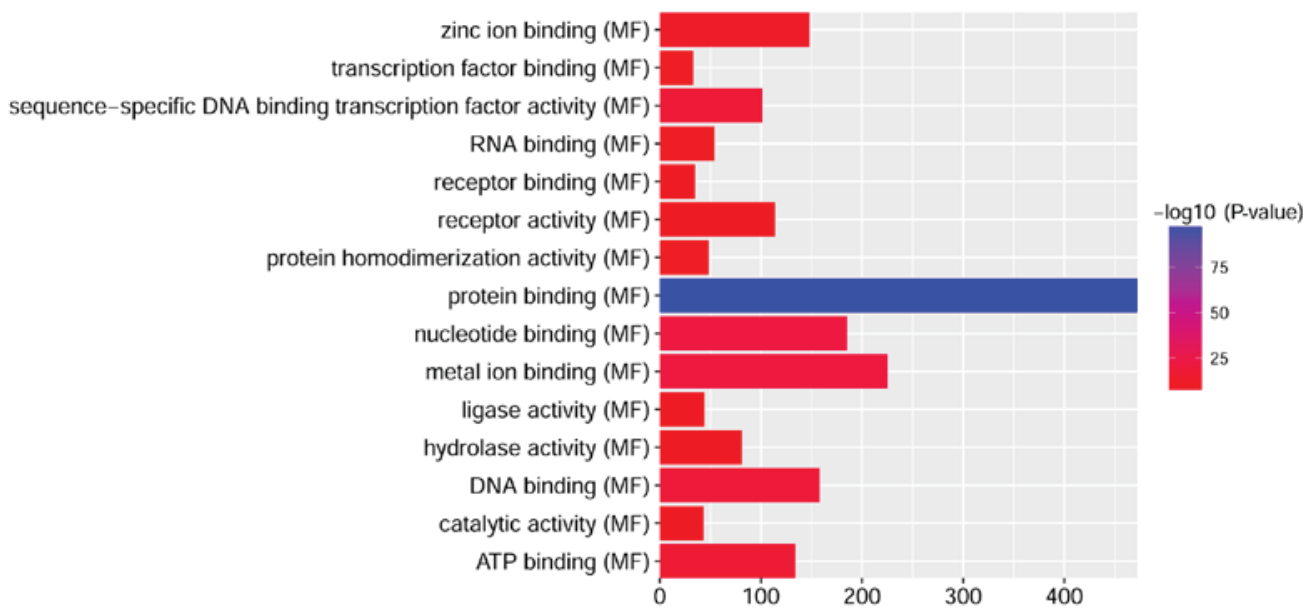

Figure 3. Top 15 significantly enriched MFs of differentially expressed genes. The x-axis represents the number of differentially expressed genes. MFs, molecular function.

'cytosol' were the most significantly enriched cellular components. 'Cytokine-cytokine receptor interaction', 'lysosome' and 'tuberculosis' were the most significantly enriched KEGG signaling pathways. The top $15 \mathrm{GO}$ terms of the DEGs are presented in Figs. 2-4. The top 15 KEGG enriched signaling pathways of the DEGs are presented in Fig. 5.

PPI network. To assess the interactions between proteins encoded by the DEGs and other proteins, the PPI network was examined and visualized using Cytoscape software. PPI networks of the top 50 upregulated and top 50 downregulated DEGs are presented in Fig. 6. The network consists of 252 nodes and 260 edges. Red and cyan ellipses represent upand downregulated proteins, respectively. Ellipses with blue or black borders represent proteins encoded by the top 100 upregulated and the top 100 downregulated DEGs, respectively. The top 13 proteins with a high degree of interaction with other proteins were heterogeneous nuclear ribonucleoprotein D $($ HNRNPD; degree $=33)$, X-ray repair cross complementing 5 (degree=20), protein kinase AMP-activated catalytic subunit a1 (PRKAA1; degree=11), RNA polymerase II subunit C (degree $=10)$, reticulon 4 (degree=9), replication protein A1 (degree=9), Y-box binding protein 3 (degree=8), DNA ligase 3 (degree $=8)$, coatomer protein complex subunit $\alpha($ degree $=8)$, tripartite motif containing 25 (degree $=8$ ), chromosome 2 containing integrin subunit $\alpha 4$ (ITGA4; degree=8), ESR1 (degree=8) and mediator complex subunit 9 (degree=6).

Establishment of TF-target genes regulatory network. In order to investigate the regulatory network of TF-target genes for children with T1D, TRANSFAC was utilized to obtain TFs for the top 10 upregulated or downregulated DEGs. A transcriptional regulatory networks consisting of 250 pairs of 


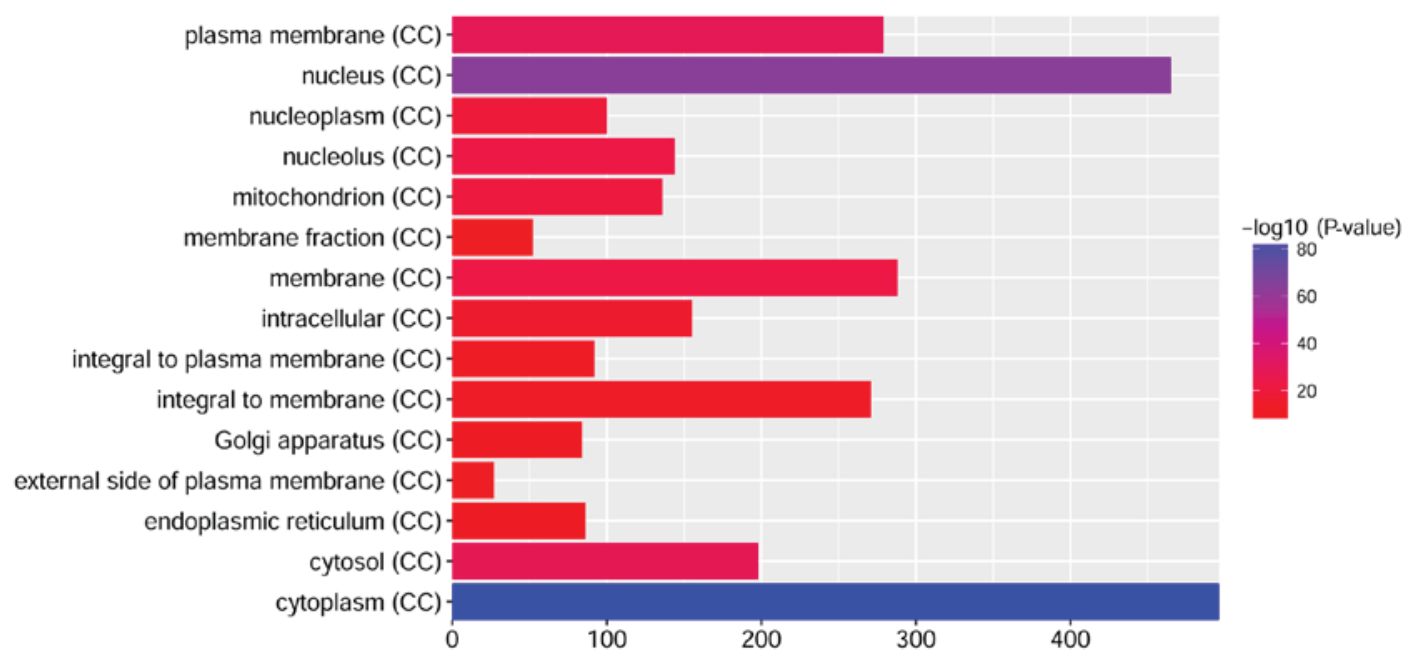

Figure 4. Top 15 significantly enriched CCs of differentially expressed genes. The x-axis represents the number of differentially expressed genes. CC, cellular component.

Table III. Top 20 differentially expressed genes in children with type 1 diabetes.

A, Upregulated genes

\begin{tabular}{llc}
\hline Gene ID & Gene symbol & P-value \\
\hline 1154 & CISH & $1.54 \times 10^{-7}$ \\
3126 & HLA-DRB4 & $1.85 \times 10^{-7}$ \\
25888 & ZNF473 & $4.29 \times 10^{-7}$ \\
4860 & NP & $7.90 \times 10^{-7}$ \\
1380 & CR2 & $3.51 \times 10^{-6}$ \\
28984 & C13orf15 & $5.07 \times 10^{-6}$ \\
9938 & ARHGAP25 & $6.64 \times 10^{-6}$ \\
2181 & ACSL3 & $1.22 \times 10^{-5}$ \\
51561 & IL23A & $1.51 \times 10^{-5}$ \\
3097 & HIVEP2 & $1.91 \times 10^{-5}$ \\
\hline
\end{tabular}

B, Downregulated genes

\begin{tabular}{lll}
\hline Gene ID & Gene symbol & P-value \\
\hline 9169 & SFRS2IP & $4.40 \times 10^{-8}$ \\
79932 & KIAA0319L & $1.01 \times 10^{-6}$ \\
3184 & HNRNPD & $1.38 \times 10^{-6}$ \\
55768 & NGLY1 & $3.77 \times 10^{-6}$ \\
6891 & TAP2 & $1.66 \times 10^{-5}$ \\
313 & AOAH & $2.43 \times 10^{-5}$ \\
7347 & UCHL3 & $2.61 \times 10^{-5}$ \\
5529 & PPP2R5E & $3.46 \times 10^{-5}$ \\
2162 & F13A1 & $4.15 \times 10^{-5}$ \\
85021 & REPS1 & $5.19 \times 10^{-5}$ \\
\hline
\end{tabular}

TF-genes involving 36 TFs was obtained (Fig. 7). Diamonds and ellipses represent TFs and genes, respectively. Red and cyan coloring represents up- and downregulation, respectively.
In this network, the top 9 downstream genes covered by the majority of TFs were ARHGAP25 (degree=12), HNRNPD (degree $=10)$, zinc finger protein 473 (degree=10), HLA-DRB4 (degree=10), IL23A (degree=9), protein phosphatase 2 regulatory subunit B' $\varepsilon$ (degree=9), acyloxyacyl hydrolase (degree $=8)$, complement C3d receptor $2($ degree $=7$ ) and $\mathrm{N}$-glycanase 1 (degree=7).

$R T$-qPCR. In the present study, four candidate genes were selected for validation: HNRNPD, PRKAA1, ITGA4 and transporter 2, ATP binding cassette subfamily B member (TAP2; Fig. 8). The results demonstrated that HNRNPD $(\mathrm{P}=0.465)$, PRKAA1 $(\mathrm{P}=0.256)$, ITGA4 $(\mathrm{P}=0.236)$ and TAP2 $(\mathrm{P}=0.295)$ were downregulated, although these results were not statistically significant.

Electronic validation of DEGs and ROC analysis. The results of electronic validation revealed that CISH, ESR1, ARHGAP25, HLA-DRB4 and IL23A were upregulated and SCAF11 was downregulated in T1D, which was consistent with the bioinformatics analysis. Expression box plots of these DEGs are presented in Fig. 9. Additionally, ROC curve analysis was performed and the AUC calculated to assess the discriminatory ability of these genes (Fig. 10). SCAF11 had the largest AUC. For children with T1D, the specificity and sensitivity of CISH were 58.3 and $93 \%$, respectively; the specificity and sensitivity of SCAF11 were 87.5 and $79.1 \%$, respectively; the specificity and sensitivity of ESR1 were 62.5 and $69.8 \%$, respectively; the specificity and sensitivity of ARHGAP25 were 79.2 and $60.5 \%$, respectively; the specificity and sensitivity of HLA-DRB4 were 62.5 and $83.7 \%$, respectively; and the specificity and sensitivity of IL23A were 70.8 and $58.1 \%$, respectively. In summary, CISH, SCAF11 and ARHGAP25 had a good diagnostic value for children with T1D as the AUC was $>0.7$.

\section{Discussion}

The present study identified that CISH and SCAF11 were the most up- and downregulated genes in children with 


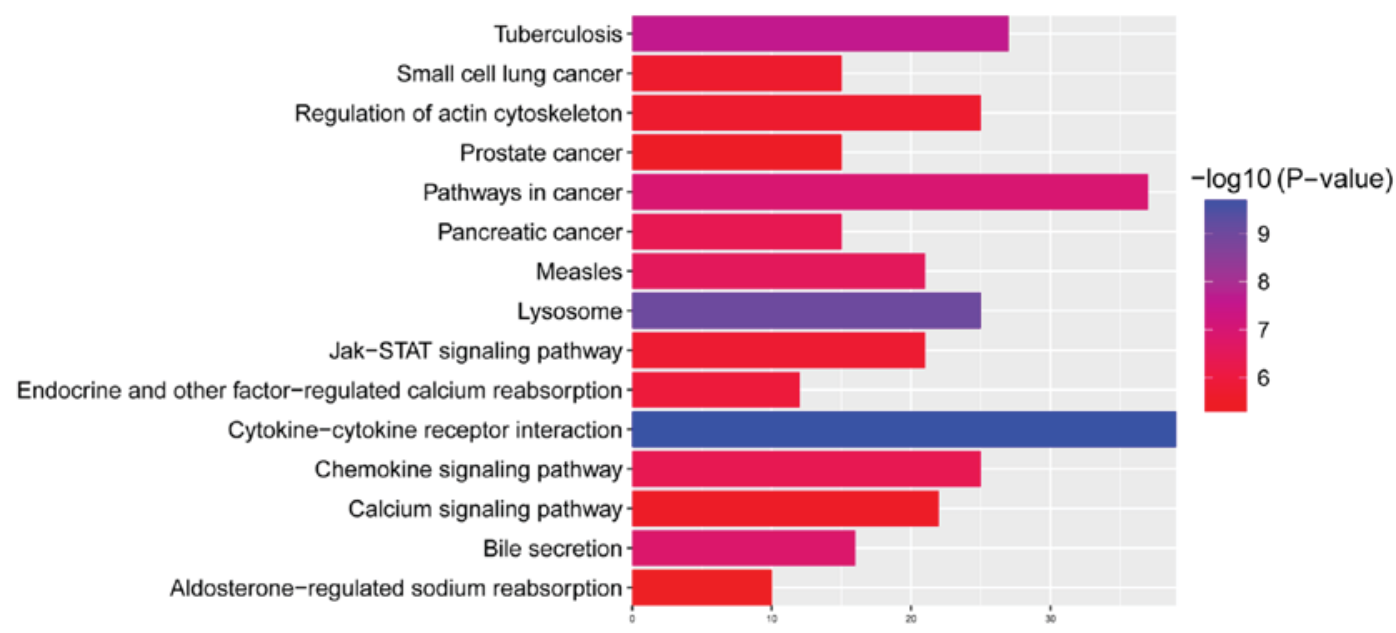

Figure 5. Top 15 significantly enriched Kyoto Encyclopedia of Genes and Genomes pathways of differentially expressed genes. The x-axis represents the number of differentially expressed genes.

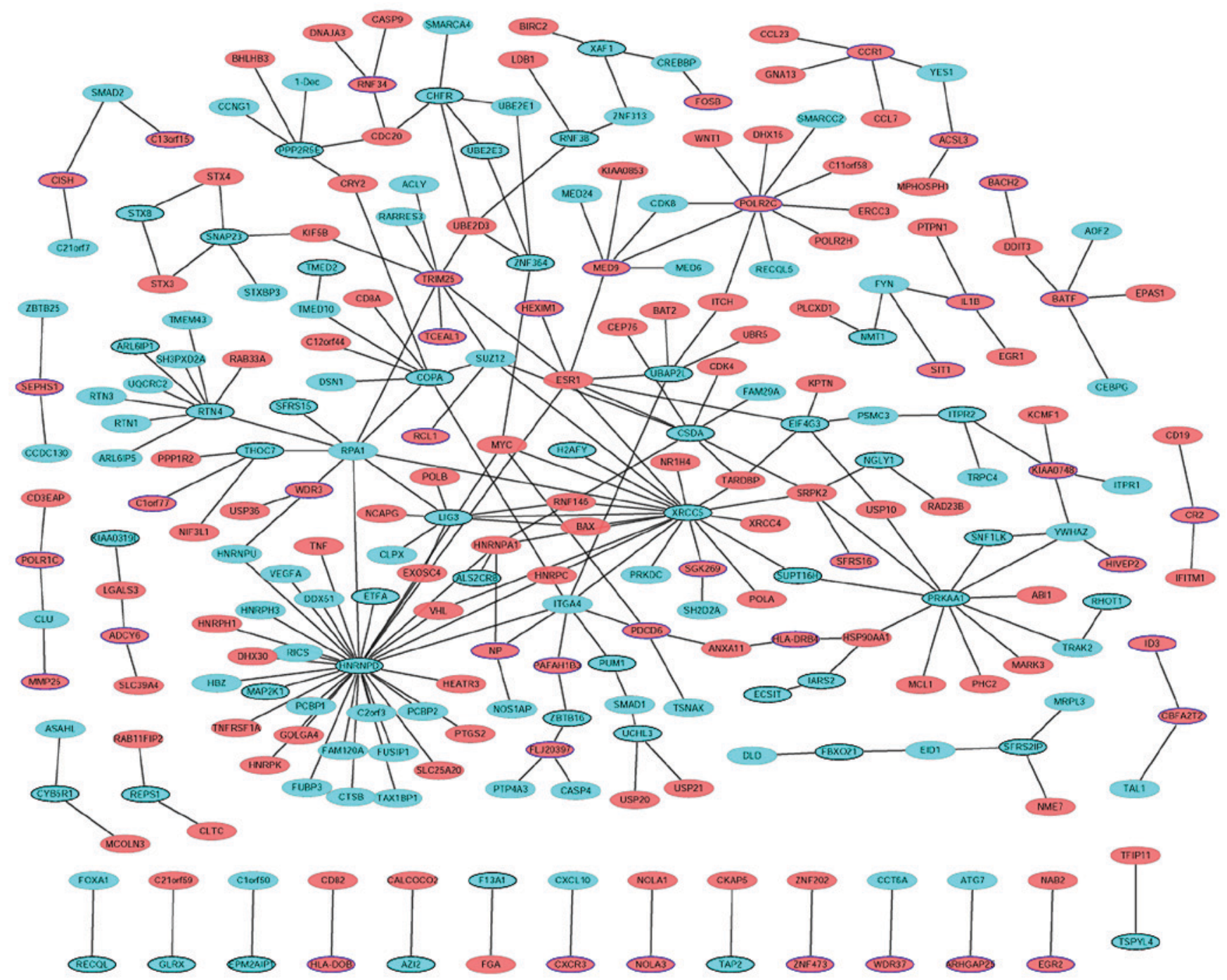

Figure 6. Protein-protein interaction networks of the top 100 DEGs. Red and cyan ellipses represent upregulated and downregulated genes, respectively. Ellipses with blue or black borders indicate proteins encoded by the top 100 upregulated and top 100 downregulated DEGs, respectively. DEGs, differentially expressed genes.

T1D. The CIS/suppressors of cytokine signaling (SOCS) family serves an important role in various immunological processes (13-16). CISH, a member of the SOCS family, is expressed in every cell and is rapidly induced by a number 


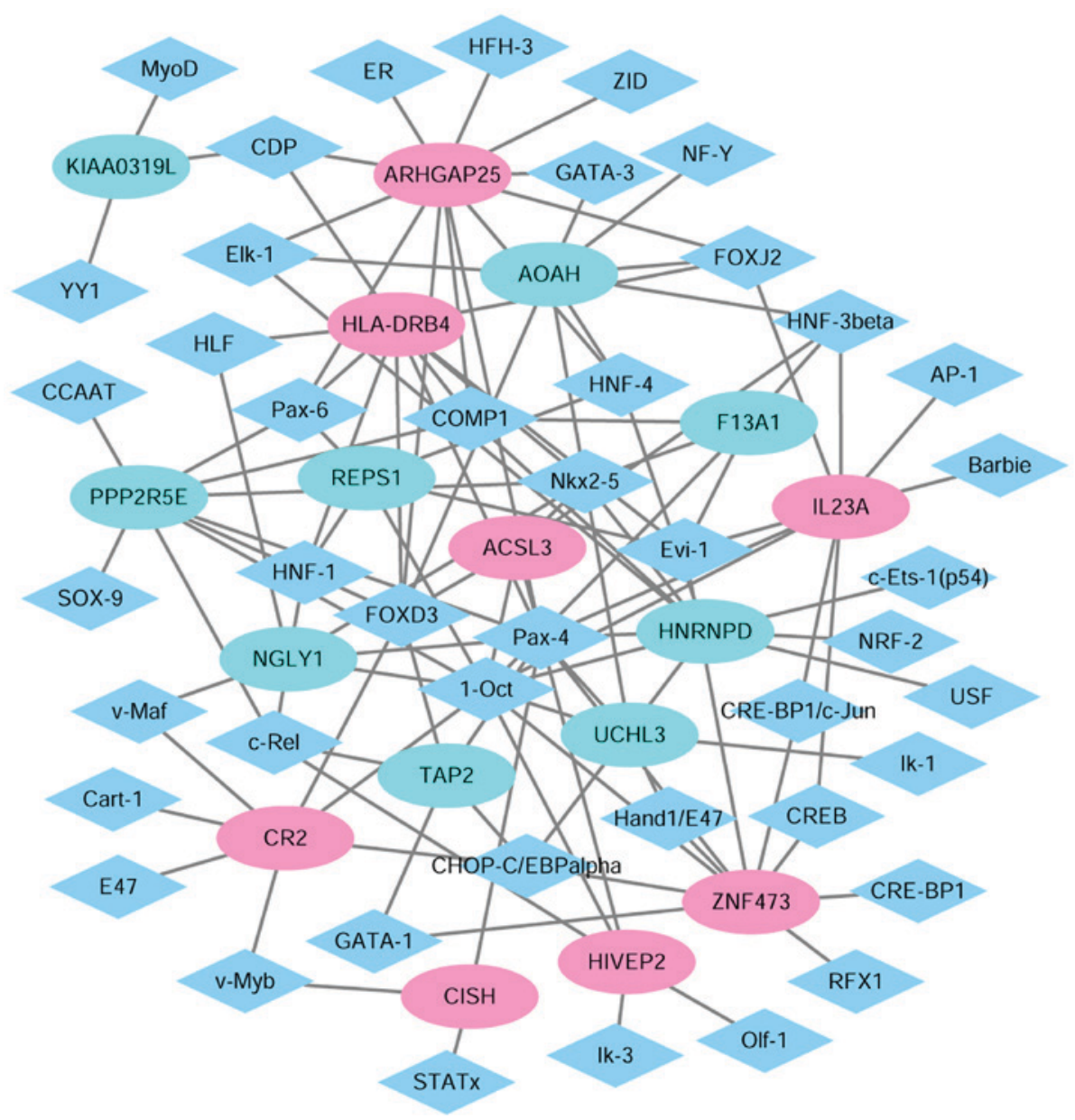

Figure 7. TF networks of the top 20 DEGs. Diamonds and ellipses represent TFs and genes, respectively. Red indicates upregulation and cyan indicates downregulation. TF, transcription factor; DEGs, differentially expressed genes.

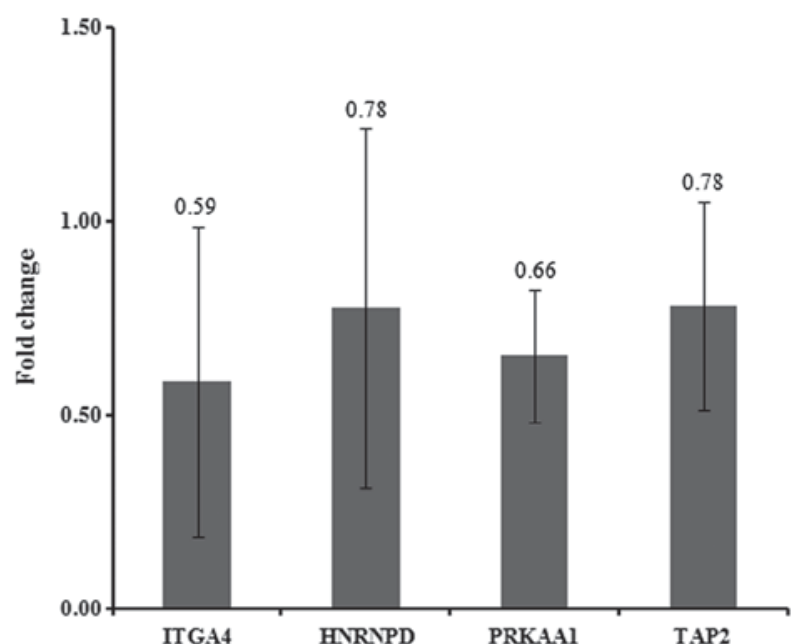

Figure 8. Expression of selected genes in the blood of children with type 1 diabetes as assessed using the reverse transcription-quantitative polymerase chain reaction. ITGA4, integrin subunit $\alpha 4$; HNRNPD, heterogeneous nuclear ribonucleoprotein D; PRKAA1, protein kinase AMP-activated catalytic subunit $\alpha 1$; TAP2, transporter 2, ATP binding cassette subfamily B member.

of stimuli, including cytokines (erythropoietin, IL-2, IL-3 and IL-5), hormones, glucose, immune complexes and Toll-like receptor ligands (17-19). Another study suggested that CISH was a critical negative regulator of IL-15 signaling in NK cells and that CISH deletion enhanced anti-tumor immunity (20). Decreased CISH expression in circulating peripheral blood mononuclear cells is associated with the severity of autoimmune diseases (21). Recently, CISH has emerged as an important modulator of $\beta$-cell insulin desensitization following prolonged glucose exposure. It has been reported that the expression and DNA methylation of CISH alter in response to hyperglycemia (22). Furthermore, the expression of CISH proteins is upregulated in islet cells from patients with T1D compared with healthy individuals (23). In mouse models, CISH is also associated with the T2D phenotype (24). SCAF11, also termed SFRS2IP, is a protein that is required for pre-mRNA splicing. Delunardo et al (25) identified that SCAF11 was involved in Behcet's disease, which has certain features of autoimmunity. In the present study, the electronic validation of CISH and SCAF11 was consistent with the bioinformatics analysis. Importantly, CISH and SCAF11 had diagnostic value for children with T1D. The results suggested that CISH and SCAF11 may serve crucial roles in autoimmunity and may be associated with the pathology of T1D in children.

In the PPI network, a number of genes with a high degree of protein interactions, including HNRNPD, PRKAA1, ITGA4 and ESR1 were identified. HNRNPD, additionally termed AUF1, is known to serve roles in mRNA regulation 

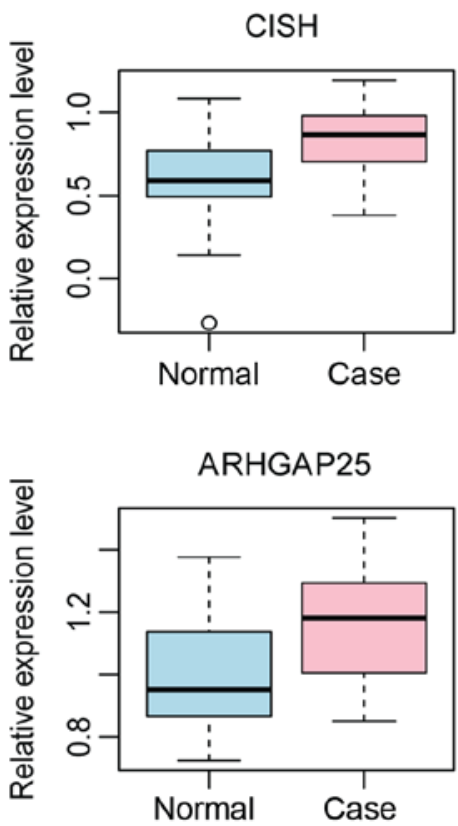

SCAF11

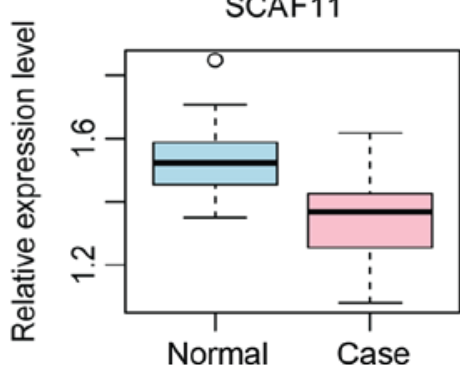

HLA-DRB4

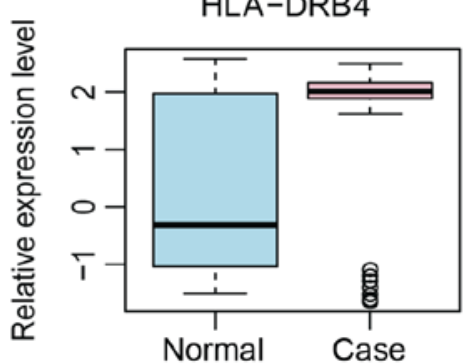

ESR1

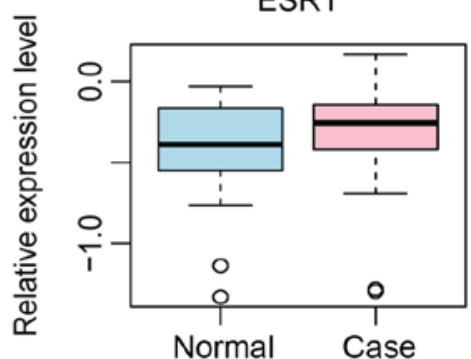

IL23A

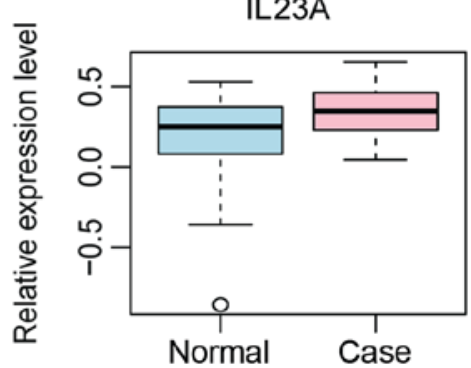

Figure 9. Box plots of selected differentially expressed genes. The x-axes illustrate control and case groups and the y-axes indicate the relative expression levels of the genes. CISH, cytokine inducible SH2 containing protein; SCAF11, SR-related CTD associated factor 11; ESR1, estrogen receptor 1; ARHGAP25, Rho GTPase activating protein 25; HLA-DRB4, major histocompatibility complex, class II, DR $\beta 4$; IL23A, interleukin 23 subunit $\alpha$.
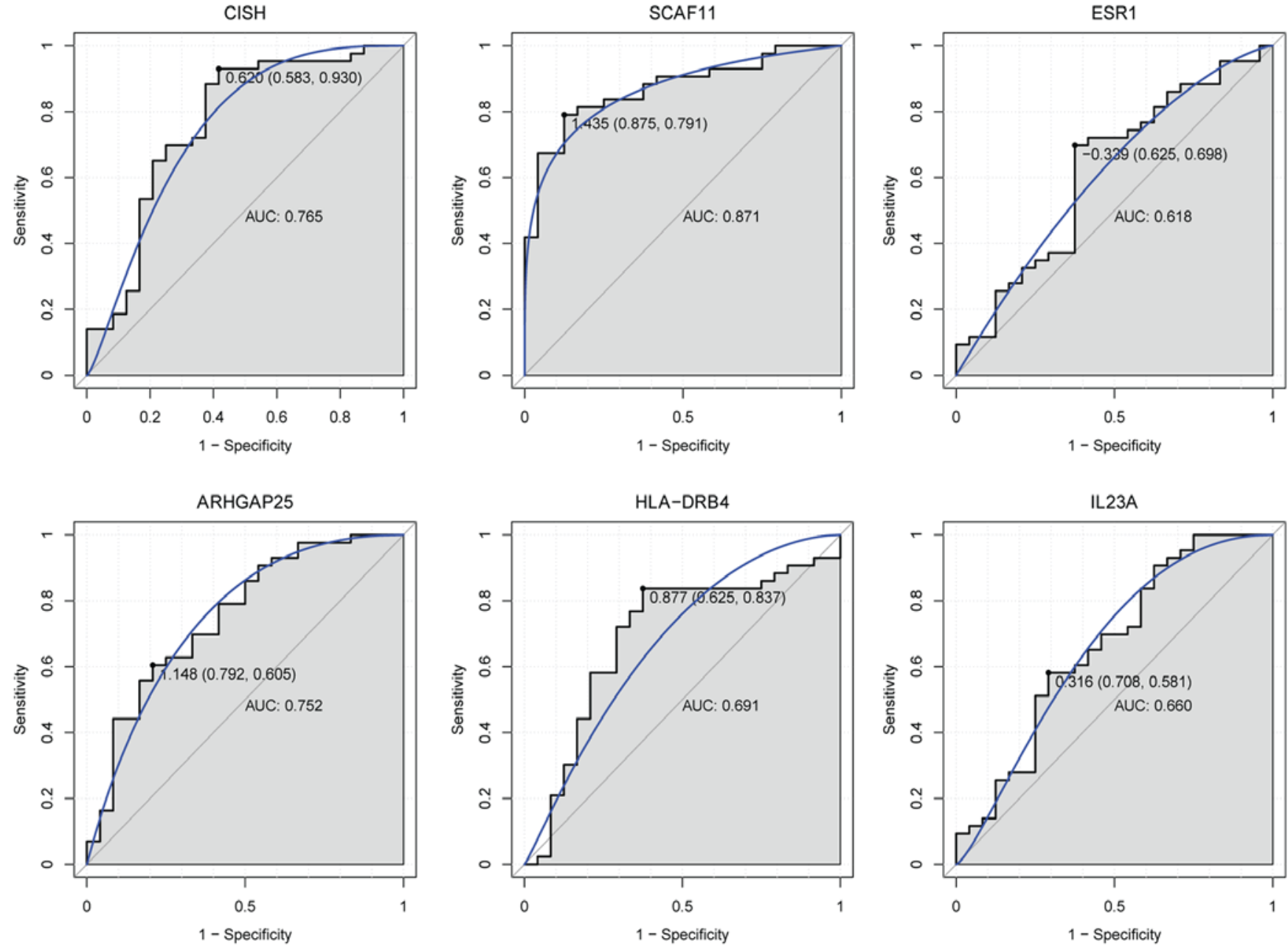

Figure 10. ROC curves of selected DEGs in children with type 1 diabetes compared with healthy controls. ROC curves were used to illustrate the diagnostic ability, sensitivity and specificity of the selected DEGs. The x-axes indicate specificity and the y-axes indicate sensitivity. ROC, receiver operating characteristic; DEGs, differentially expressed genes; CISH, cytokine inducible SH2 containing protein; SCAF11, SR-related CTD associated factor 11; ESR1, estrogen receptor 1; ARHGAP25, Rho GTPase activating protein 25; HLA-DRB4, major histocompatibility complex, class II, DR $\beta 4$; IL23A, interleukin 23 subunit $\alpha$. 
and the stability of proteins in the inflammatory response and developmental processes (26). It has been demonstrated that HNRNPD knockdown decreases glucose deprivation-induced apoptosis, whereas HNRNPD overexpression has the opposite effect (27). The present study first identified that HNRNPD expression was downregulated in the blood of children with T1D. Furthermore, the results of the RT-qPCR validation were consistent with the bioinformatics analysis. The results further suggested that HNRNPD is associated with the progression of T1D in children.

In mammals, the PRKAA1 protein is one of the subunits of 5'-adenosine monophosphate-activated protein kinase, an important metabolic switch that governs glucose metabolism in response to alterations in intracellular energy levels in pancreatic $\beta$-cells (28). PRKAA1 activation results in glucose transporter upregulation. It has been reported that PRKAA1 serves roles in gluconeogenesis and is important for glucose-stimulated insulin secretion from pancreatic $\beta$-cells $(29,30)$. It has also been reported that PRKAA1 expression is significantly decreased in islets in T2D (31). To the best of the authors' knowledge, the present study is the first to report that that PRKAA1 is downregulated in the blood of children with T1D. The results suggested that PRKAA1 may serve a vital role in the pancreatic $\beta$-cells of children with T1D.

Nalls et al (32) reported that specific loci that regulate immune cell frequency on ITGA4 are associated with immune-mediated disorders. In addition, the rs1449263 polymorphism of ITGA4 has been studied in a number of autoimmune diseases (33). It has been identified that the rs13010713 polymorphism of ITGA4 is present in T1D (34). The present study identified that ITGA4 was downregulated in the blood of children with T1D. Notably, the results of RT-qPCR validated the expression of ITGA4. The present study provided additional evidence that ITGA4 serves important roles in the pathogenesis of T1D in children.

ESR1 is expressed by thymocytes, T cells, B lymphocytes, thymic epithelial cells and non-hematopoietic bone marrow cells, which serve roles in the functioning of the immune system (35-41). Ribas et al (42) identified that ESR1 serves a key role in protecting against and reducing inflammation, in addition to a key role in glucose tolerance (43). It is known that men with the ESR1 null mutation exhibit insulin resistance and impaired glucose tolerance (44). It has also been demonstrated that ESR1 polymorphisms, including variants in the intron 1-intron 2 region, are positively associated with the T2D phenotype (45). In addition, ESR1 is a DEG associated with islet function and the exocrine function of the pancreas in patients with T1D (46). The present study identified that ESR1 was upregulated in the blood of children with T1D, which suggested that ESR1 is closely associated with the pathology of children with T1D.

The TF-target genes regulatory network for children with T1D was obtained and investigated. In this network, a number of high-degree target genes of TFs were identified, including ARHGAP25, HLA-DRB4 and IL23A. ARHGAP25, a GTPase-activating protein for Rac, is upregulated in alveolar rhabdomyosarcoma and is required for cell invasion (47). It has been reported that ARHGAP25 is an immune gene (48) and the rs6714065 and rs7605681 polymorphisms of ARHGAP25 have been identified in T2D (49). In the present study, ARHGAP25 was upregulated in the blood of children with T1D. Notably, it was identified that ARHGAP25 had potential diagnostic value for children with T1D. This suggested that ARHGAP25 may serve an important role in the development of T1D in children.

HLA-DRB4, additionally termed DR4, is important to the adaptive immune system. Genetic variation in the HLA region is associated with diabetes risk (50) and the HLA class II allele confers genetic susceptibility to T1D (51). HLA-DRB4 is an immunity-associated gene that is differentially expressed in the intestine of insulin-resistant subjects (52). It has been demonstrated that HLA-DRB4 confers susceptibility to T1D (53). HLA-DRB4 is differentially expressed in the immune system and serves roles in antigen presentation in the islets of T1D patients (46). It has been reported that HLA-DRB4 expression is significantly associated with childhood T1D (54). The present study also identified an association between HLA-DRB4 and childhood T1D, which was in agreement with a previous study (54).

IL23A is an autoimmune risk factor that belongs to the IL-12 heterodimeric cytokine family (55). It has been reported that genetic variation in IL23A has an influence on T2D (56) and that IL23A overexpression occurs in patients with T1D (57). In the present study, IL23A expression was identified to be upregulated in the blood of patients with childhood T1D. The results suggested that IL23A may be involved in the pathogenesis of childhood T1D.

TAP2 is associated with a number of autoimmune diseases (58). Vejbaesya et al (59) reported that TAP2 served important roles in HLA-associated diseases and the immune response, including systemic lupus erythematosus and rheumatoid arthritis (60). It has been reported that TAP2 is a risk factor for T1D (61). The present study identified that TAP2 was downregulated in the blood of children with T1D. The results of RT-qPCR confirmed this, further suggesting that TAP2 served an important role in the development of childhood T1D.

In summary, the results of the present study revealed a number of genes that are differentially expressed in T1D, including CISH, SCAF11, HNRNPD, PRKAA1, ITGA4, ESR1, ARHGAP25, HLA-DRB4, IL23A and TAP2. These genes may serve a role in the pathogenesis of childhood T1D. CISH, SCAF11 and ARHGAP25 possess potential diagnostic value for children with T1D. However, there are a number of limitations to the present study. First, the sample size used for RT-qPCR was small; future studies may utilize a larger study group. Second, the biological functions of the identified genes were not investigated. In future, in vivo and in vitro experiments may be performed to verify the results of the present study.

\section{Acknowledgements}

The authors would like to thank Beijing Yangshen Bioinformatic Technology (Beijing, China) for their assistance with data analysis.

\section{Funding}

No funding was received. 


\section{Availability of data and materials}

All data generated or analyzed during this study are included in this published article.

\section{Authors' contributions}

LQ and HS analyzed the data, MD designed the study and LQ wrote the manuscript. All authors read and approved the final version of the manuscript.

\section{Ethics approval and consent to participate}

Ethical approval was obtained from the Ethics Committee of Shandong Jining No. 1 People's Hospital (Jining, China). Written informed consent was obtained from all subjects.

\section{Patient consent for publication}

Written informed consent was obtained from all subjects.

\section{Competing interests}

The authors declare that they have no competing interests.

\section{References}

1. American Diabetes Association: Diagnosis and classification of diabetes mellitus. Diabetes Care 32 (Suppl 1): S62-S69, 2009.

2. Chentoufi AA, Binder NR, Berka N, Abunadi T and Polychronakos C: Advances in type I diabetes associated tolerance mechanisms. Scand J Immunol 68: 1-11, 2008.

3. Dotta F, Censini S, van Halteren AG, Marselli L, Masini M, Dionisi S, Mosca F, Boggi U, Muda AO, Del Prato S, et al: Coxsackie B4 virus infection of beta cells and natural killer cell insulitis in recent-onset type 1 diabetic patients. Proc Natl Acad Sci USA 104: 5115-5120, 2007.

4. Richardson SJ, Willcox A, Bone AJ, Foulis AK and Morgan NG: The prevalence of enteroviral capsid protein vp1 immunostaining in pancreatic islets in human type 1 diabetes. Diabetologia 52: 1143-1151, 2009.

5. Craig ME, Hattersley A and Donaghue KC: Definition, epidemiology and classification of diabetes in children and adolescents. Pediatr Diabetes 10 (Suppl 12): S3-S12, 2009.

6. Dabelea D, Mayer-Davis EJ, Saydah S, Imperatore G, Linder B, Divers J, Bell R, Badaru A, Talton JW, Crume T, et al: Prevalence of type 1 and type 2 diabetes among children and adolescents from 2001 to 2009. JAMA 311: 1778-1786, 2014.

7. Aguiree F, Brown A, Cho NH, Dahlquist G, Dodd S, Dunning T, Hirst M, Hwang C, Magliano D, Patterson C, et al: IDF Diabetes Atlas: Sixth edition. Int Diabetes Fed, 2013.

8. American Diabetes Association: Diagnosis and classification of diabetes mellitus. Diabetes Care 33 (Suppl 1): S62-S69, 2010.

9. Ritchie ME, Phipson B, Wu D, Hu Y, Law CW, Shi W and Smyth GK: limma powers differential expression analyses for RNA-sequencing and microarray studies. Nucleic Acids Res 43: e47, 2015.

10. Marot G, Foulley JL, Mayer CD and Jaffrézic F: Moderated effect size and P-value combinations for microarray meta-analyses. Bioinformatics 25: 2692-2699, 2009.

11. Livak KJ and Schmittgen TD: Analysis of relative gene expression data using real-time quantitative PCR and the 2(-Delta Delta C(T)) method. Methods 25: 402-408, 2001.

12. Robin X, Turck N, Hainard A, Tiberti N, Lisacek F, Sanchez JC and Müller M: pROC: An open-source package for $\mathrm{R}$ and $\mathrm{S}^{+}$to analyze and compare ROC curves. BMC Bioinformatics 12: 77, 2011.

13. Chinen T, Komai K, Muto G, Morita R, Inoue N, Yoshida H, Sekiya T, Yoshida R, Nakamura K, Takayanagi R and Yoshimura A: Prostaglandin E2 and SOCS1 have a role in intestinal immune tolerance. Nat Commun 2: 190, 2011.
14. Hiwatashi K, Tamiya T, Hasegawa E, Fukaya T, Hashimoto M, Kakoi K, Kashiwagi I, Kimura A, Inoue N, Morita R, et al: Suppression of SOCS3 in macrophages prevents cancer metastasis by modifying macrophage phase and MCP2/CCL8 induction. Cancer Lett 308: 172-180, 2011.

15. Takahashi R, Nishimoto S, Muto G, Sekiya T, Tamiya T, Kimura A, Morita R, Asakawa M, Chinen T and Yoshimura A: SOCS1 is essential for regulatory $\mathrm{T}$ cell functions by preventing loss of Foxp3 expression as well as IFN-\{gamma\} and IL-17A production. J Exp Med 208: 2055-2067, 2011.

16. Tamiya T, Kashiwagi I, Takahashi R, Yasukawa $H$ and Yoshimura A: Suppressors of cytokine signaling (SOCS) proteins and JAK/STAT pathways: Regulation of T-cell inflammation by SOCS1 and SOCS3. Arterioscler Thromb Vasc Biol 31: 980-985, 2011.

17. Matsumoto A, Masuhara M, Mitsui K, Yokouchi M, Ohtsubo M, Misawa H, Miyajima A and Yoshimura A: CIS, a cytokine inducible SH2 protein, is a target of the JAK-STAT5 pathway and modulates STAT5 activation. Blood 89: 3148-3154, 1997.

18. Yoshimura A, Ohkubo T, Kiguchi T, Jenkins NA, Gilbert DJ, Copeland NG, Hara T and Miyajima A: A novel cytokine-inducible gene CIS encodes an SH2-containing protein that binds to tyrosine-phosphorylated interleukin 3 and erythropoietin receptors. EMBO J 14: 2816-2826, 1995.

19. Yoshimura A, Naka T and Kubo M: SOCS proteins, cytokine signalling and immune regulation. Nat Rev Immunol 7: 454-465, 2007.

20. Delconte RB, Kolesnik TB, Dagley LF, Rautela J, Shi W, Putz EM, Stannard K, Zhang JG, Teh C, Firth M, et al: CIS is a potent checkpoint in NK cell-mediated tumor immunity. Nat Immunol 17: 816-824, 2016.

21. McCormick SM and Heller NM: Regulation of macrophage, dendritic cell and microglial phenotype and function by the SOCS proteins. Front Immunol 6: 549, 2015.

22. Tros F, Meirhaeghe A, Hadjadj S, Amouyel P, Bougneres P and Fradin D: Hypomethylation of the promoter of the catalytic subunit of protein phosphatase $2 \mathrm{~A}$ in response to hyperglycemia. Physiol Rep 2: pii: e12076, 2014.

23. Santangelo C, Scipioni A, Marselli L, Marchetti P and Dotta F: Suppressor of cytokine signaling gene expression in human pancreatic islets: Modulation by cytokines. Eur J Endocrinol 152: 485-489, 2005.

24. Malle EK, Zammit NW, Walters SN, Koay YC, Wu J, Tan BM, Villanueva JE, Brink R, Loudovaris T, Cantley J, et al: Nuclear factor $\kappa \mathrm{B}$-inducing kinase activation as a mechanism of pancreatic $\beta$ cell failure in obesity. J Exp Med 212: 1239-1254, 2015.

25. Delunardo F, Conti F, Margutti P, Alessandri C, Priori R, Siracusano A, Riganò R, Profumo E, Valesini G, Sorice M and Ortona E: Identification and characterization of the carboxy-terminal region of Sip-1, a novel autoantigen in Behçet's disease. Arthritis Res Ther 8: R71, 2006.

26. Moore AE, Chenette DM, Larkin LC and Schneider RJ: Physiological networks and disease functions of RNA-binding protein AUF1. Wiley Interdiscip Rev RNA 5: 549-564, 2014.

27. Gao X, Dong H, Lin C, Sheng J, Zhang F, Su J and Xu Z: Reduction of AUF1-mediated follistatin mRNA decay during glucose starvation protects cells from apoptosis. Nucleic Acids Res 42: 10720-10730, 2014.

28. Gleason CE, Lu D, Witters LA, Newgard CB and Birnbaum MJ: The role of AMPK and mTOR in nutrient sensing in pancreatic beta-cells. J Biol Chem 282: 10341-10351, 2007.

29. Maruthur NM, Gribble MO, Bennett WL, Bolen S, Wilson LM, Balakrishnan P, Sahu A, Bass E, Kao WH and Clark JM: The pharmacogenetics of type 2 diabetes: A systematic review. Diabetes Care 37: 876-886, 2014.

30. Sun G, Tarasov AI, McGinty J, McDonald A, da Silva Xavier G, Gorman T, Marley A, French PM, Parker H, Gribble F, et al: Ablation of AMP-activated protein kinase alpha1 and alpha2 from mouse pancreatic beta cells and RIP2.Cre neurons suppresses insulin release in vivo. Diabetologia 53: 924-936, 2010.

31. da Silva Xavier G, Farhan H, Kim H, Caxaria S, Johnson P, Hughes S, Bugliani M, Marselli L, Marchetti P, Birzele F, et al: Per-arnt-sim (PAS) domain-containing protein kinase is downregulated in human islets in type 2 diabetes and regulates glucagon secretion. Diabetologia 54: 819-827, 2011.

32. Nalls MA, Couper DJ, Tanaka T, van Rooij FJ, Chen MH, Smith AV, Toniolo D, Zakai NA, Yang Q, Greinacher A, et al: Multiple loci are associated with white blood cell phenotypes. PLoS Genet 7: e1002113, 2011. 
33. Chu M, Yang P, Hou S, Li F, Chen Y and Kijlstra A: Behcet's disease exhibits an increased osteopontin serum level in active stage but no association with osteopontin and its receptor gene polymorphisms. Hum Immunol 72: 525-529, 2011.

34. Gutierrez-Achury J, Romanos J, Bakker SF, Kumar V, de Haas EC, Trynka G, Ricaño-Ponce I and Steck A; Type 1 Diabetes Genetics Consortium, Chen WM, et al: Contrasting the genetic background of type 1 diabetes and celiac disease autoimmunity. Diabetes Care 38 (Suppl 2): S37-S44, 2015.

35. Korn-Lubetzki I, Kahana E, Cooper G and Abramsky O: Activity of multiple sclerosis during pregnancy and puerperium. Ann Neurol 16: 229-231, 1984.

36. Ito A, Bebo BF Jr, Matejuk A, Zamora A, Silverman M, Fyfe-Johnson A and Offner H: Estrogen treatment down-regulates TNF-alpha production and reduces the severity of experimental autoimmune encephalomyelitis in cytokine knockout mice. J Immunol 167: 542-552, 2001.

37. Bebo BF Jr, Fyfe-Johnson A, Adlard K, Beam AG, Vandenbark AA and Offner H: Low-dose estrogen therapy ameliorates experimental autoimmune encephalomyelitis in two different inbred mouse strains. J Immunol 166: 2080-2089, 2001

38. Matejuk A, Adlard K, Zamora A, Silverman M, Vandenbark AA and Offner $\mathrm{H}$ : 17 beta-estradiol inhibits cytokine, chemokine, and chemokine receptor mRNA expression in the central nervous system of female mice with experimental autoimmune encephalomyelitis. J Neurosci Res 65: 529-542, 2001.

39. Matejuk A, Dwyer J, Zamora A, Vandenbark AA and Offner $\mathrm{H}$ Evaluation of the effects of 17beta-estradiol (17beta-e2) on gene expression in experimental autoimmune encephalomyelitis using DNA microarray. Endocrinology 143: 313-319, 2002.

40. Evron S, Brenner T and Abramsky O: Suppressive effect of pregnancy on the development of experimental allergic encephalomyelitis in rabbits. Am J Reprod Immunol 5: 109-113, 1984.

41. Jansson L, Olsson T and Holmdahl R: Estrogen induces a potent suppression of experimental autoimmune encephalomyelitis and collagen-induced arthritis in mice. J Neuroimmunol 53: 203-207, 1994.

42. Ribas V, Nguyen MT, Henstridge DC, Nguyen AK, Beaven SW, Watt MJ and Hevener AL: Impaired oxidative metabolism and inflammation are associated with insulin resistance in ERalpha-deficient mice. Am J Physiol Endocrinol Metab 298: E304-E319, 2010.

43. Ricchiuti V, Lian CG, Oestreicher EM, Tran L, Stone JR, Yao T, Seely EW, Williams GH and Adler GK: Estradiol increases angiotensin II type 1 receptor in hearts of ovariectomized rats. J Endocrinol 200: 75-84, 2009.

44. Smith EP, Boyd J, Frank GR, Takahashi H, Cohen RM, Specker B, Williams TC, Lubahn DB and Korach KS: Estrogen resistance caused by a mutation in the estrogen-receptor gene in a man. $\mathrm{N}$ Engl J Med 331: 1056-1061, 1994.

45. Speer G, Cseh K, Winkler G, Vargha P, Braun E, Takács I and Lakatos P: Vitamin D and estrogen receptor gene polymorphisms in type 2 diabetes mellitus and in android type obesity. Eur J Endocrinol 144: 385-389, 2001.

46. Planas R, Carrillo J, Sanchez A, de Villa MC, Nuñez F, Verdaguer J, James RF, Pujol-Borrell R and Vives-Pi M: Gene expression profiles for the human pancreas and purified islets in type 1 diabetes: New findings at clinical onset and in long-standing diabetes. Clin Exp Immunol 159: 23-44, 2010.

47. Thuault S, Comunale F, Hasna J, Fortier M, Planchon D, Elarouci N, De Reynies A, Bodin S, Blangy A and Gauthier-Rouvière C: The RhoE/ROCK/ARHGAP25 signaling pathway controls cell invasion by inhibition of Rac activity. Mol Biol Cell 27: 2653-2661, 2016.

48. Chifman J, Pullikuth A, Chou JW, Bedognetti D and Miller LD: Conservation of immune gene signatures in solid tumors and prognostic implications. BMC Cancer 16: 911, 2016.
49. Hasstedt SJ, Highland HM, Elbein SC, Hanis CL and Das SK; American Diabetes Association GENNID Study Group: Five linkage regions each harbor multiple type 2 diabetes genes in the African American subset of the GENNID study. J Hum Genet 58: 378-383, 2013.

50. Regnell SE and Lernmark $\AA$ : Early prediction of autoimmune (type 1) diabetes. Diabetologia 60: 1370-1381, 2017.

51. Lambert AP, Gillespie KM, Thomson G, Cordell HJ, Todd JA, Gale EA and Bingley PJ: Absolute risk of childhood-onset type 1 diabetes defined by human leukocyte antigen class II genotype: A population-based study in the United Kingdom. J Clin Endocrinol Metab 89: 4037-4043, 2004.

52. Veilleux A, Mayeur S, Bérubé JC, Beaulieu JF, Tremblay E, Hould FS, Bossé Y, Richard D and Levy E: Altered intestinal functions and increased local inflammation in insulin-resistant obese subjects: A gene-expression profile analysis. BMC Gastroenterol 15: 119, 2015.

53. Noble JA, Valdes AM, Cook M, Klitz W, Thomson G and Erlich HA: The role of HLA class II genes in insulin-dependent diabetes mellitus: Molecular analysis of 180 Caucasian, multiplex families. Am J Hum Genet 59: 1134-1148, 1996.

54. Zhao LP, Alshiekh S, Zhao M, Carlsson A, Larsson HE, Forsander G, Ivarsson SA, Ludvigsson J, Kockum I, Marcus C, et al: Next-generation sequencing reveals that HLA-DRB3, -DRB4, and -DRB 5 may be associated with islet autoantibodies and risk for childhood type 1 diabetes. Diabetes 65: 710-718, 2016.

55. Vandenbroeck K: Cytokine gene polymorphisms and human autoimmune disease in the era of genome-wide association studies. J Interferon Cytokine Res 32: 139-151, 2012.

56. Eiris N, González-Lara L, Santos-Juanes J, Queiro R, Coto E and Coto-Segura P: Genetic variation at IL12B, IL23R and IL23A is associated with psoriasis severity, psoriatic arthritis and type 2 diabetes mellitus. J Dermatol Sci 75: 167-172, 2014.

57. Evangelista AF, Collares CV, Xavier DJ, Macedo C, Manoel-Caetano FS, Rassi DM, Foss-Freitas MC, Foss MC, Sakamoto-Hojo ET, Nguyen C, et al: Integrative analysis of the transcriptome profiles observed in type 1, type 2 and gestational diabetes mellitus reveals the role of inflammation. BMC Med Genomics 7: 28, 2014.

58. Torres AR, Westover JB and Rosenspire AJ: HLA immune function genes in autism. Autism Res Treat 2012: 959073, 2012

59. Vejbaesya S, Luangtrakool P, Luangtrakool K, Sermduangprateep C and Parivisutt L: Analysis of TAP and HLA-DM polymorphism in thai rheumatoid arthritis. Hum Immunol 61: 309-313, 2000.

60. Dai D, Chen Y, Ru P, Zhou X, Tao J, Ye H, Hong Q, Tang L, Pan G, Lin D, et al: Significant association between TAP2 polymorphisms and rheumatoid arthritis: A meta-analysis. Diagn Pathol 9: 129, 2014.

61. Sirota M, Schaub MA, Batzoglou S, Robinson WH and Butte AJ: Autoimmune disease classification by inverse association with SNP alleles. PLoS Genet 5: e1000792, 2009.

62. Kaizer EC, Glaser CL, Chaussabel D, Banchereau J, Pascual V and White PC: Gene expression in peripheral blood mononuclear cells from children with diabeters. J Clin Endocrinol Metab 92 . 3705-3711, 2007.

63. Irvine KM, Gallego P, An X, Best SE, Thomas G, Wells C, Harris M, Cotterill A and Thomas R: Peripheral blood monocyte gene expression profile clinically stratifies patients with recentonset type 1 diabetes. Diabetes 61: 1281-1290, 2012.

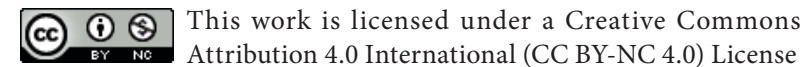

